\title{
Lipid Droplets in Health and Disease
}

\author{
Gizem Onal ${ }^{1}$, Ozlem Kutlu², Devrim Gozuacik ${ }^{3}$ and Serap Dokmeci Emre ${ }^{1 *}$ (D)
}

\begin{abstract}
Lipids are essential building blocks synthesized by complex molecular pathways and deposited as lipid droplets (LDs) in cells. LDs are evolutionary conserved organelles found in almost all organisms, from bacteria to mammals. They are composed of a hydrophobic neutral lipid core surrounding by a phospholipid monolayer membrane with various decorating proteins. Degradation of LDs provide metabolic energy for divergent cellular processes such as membrane synthesis and molecular signaling. Lipolysis and autophagy are two main catabolic pathways of LDs, which regulate lipid metabolism and, thereby, closely engaged in many pathological conditons. In this review, we first provide an overview of the current knowledge on the structural properties and the biogenesis of LDs. We further focus on the recent findings of their catabolic mechanism by lipolysis and autophagy as well as their connection ragarding the regulation and function. Moreover, we discuss the relevance of LDs and their catabolismdependent pathophysiological conditions.
\end{abstract}

Keywords: Lipid droplets, lipolysis, lipophagy, chaperone-mediated autophagy

\section{Background}

Many living organisms store lipids in their cells to produce metabolic energy, in case of insufficient energy sources. Cells preserve lipids by converting them into neutral lipids, such as triacylglycerides (TAG) and sterol esters (SE). These type of lipids are deposited in lipid droplets (LDs) which are also termed as adiposomes, lipid bodies or oil bodies [1]. For a long time, LDs were accepted as inert intracellular vesicles storing neutral lipids in all living organisms. However, recent advances in functional analysis techniques, imaging methods, lipidomics and proteomics technology offer scientists a better understanding of biological properties and functions of LDs. In the last couple of years, many structural and functional proteins were identified and characterized on the surface of LDs, and they were named as perilipins (PLINs) [2]. In addition to their role in energy metabolism, LDs play a role in various cellular events, ranging from protein degradation, sequestration of transcription factors and chromatin components to generation of lipid ligands for certain nuclear receptors, and they serve as fatty acid trafficking nodes [3-5]. Moreover, LDs might be hijacked by various pathogens. Due to these diverse functions, abnormalities of LDs were associated with many pathological conditions [6-8].

\footnotetext{
* Correspondence: semre@hacettepe.edu.tr

'Department of Medical Biology, Hacettepe University, 06100 Ankara, Turkey Full list of author information is available at the end of the article
}

The catabolism of LDs into free fatty acids (FAs) is a crucial cellular pathway that is required to generate energy in the form of ATP, and to provide building blocks for biological membrane and hormone synthesis. Lipolysis is a biochemical catabolic pathway that relies on the direct activation of LD-associated lipases, such as adipose triglyceride lipase (ATGL), hormone-sensitive lipase (HSL) and monoglyceride lipase (MGL) [9, 10]. Together with regulatory protein factors ATGL activator (comperative gene identification-58, CGI-58) and ATGL inhibitor (G0/G1 switch protein 2, G0S2), these lipases constitute the basis for the lipolytic machinery in cells.

Autophagy is one of the two major degradation pathways in cells supporting cell survival by recycling metabolic components under stress conditions (Ubiquitin-proteasome system being the other pathway). It is initiated by sequestering cytosolic organelles or macromolecules in doublemembrane vesicles and delivering them to lysosomes for degradation by the lytic enzymes therein. Cellular building blocks are then released back to cytosol and recycled to ensure cellular homeostasis $[11,12]$. Basic machanism of autophagy is classified into three different types: Macroautophagy, chaperone-mediated autophagy (CMA) and microautophagy. Macroautophagy is a well-studied pathway, targeting large substrates such as toxic aggregates and degenerated organelles in a selective or nonselective manner [13]. Chaperone-mediated autophagy (CMA) is a selective form of autophagy, targeting specific 
proteins through the recognition activity of chaperone protein heat shock cognate 70 (Hsc70). Hsc70 delivers the substrates to the lysosomal lumen via lysosomalassociated protein 2a (LAMP2a) [14, 15]. Microautophagy degrades cytoplasmic cargos through a organized invagination of lysosomal membranes and direct engulfment [16].

Recent investigations defined another selective form of macroautophagy termed "lipophagy". In this autophagy form, LD degradation is controlled by the association of membrane GTPase Rab7 with LDs [17, 18]. Moreover, a significant role of CMA was recently identified in selective degradation of a unique LD-coat protein family called PLINs [19, 20]. Therefore, autophagy pathways play a crucial role in lipid metabolism and the number of publications in this relatively new field is growing exponentially.

In contrast with the traditional view that LDs are simple lipid storage vesicles, because of their dynamic nature and multifunctionality they are today accepted as a distinct intracellular organelles. Recent studies underline physiological importance of these multifunctional organelles, particularly in the context of lipolysis and selective autophagy mechanisms of lipophagy and CMA. Here, we will first summarize biological properties of LDs and then focus on recent findings on molecular regulation of lipolytic and autophagic mechanism. Furthermore, we will discuss the relevance of LDs and related catabolic mechanisms for pathophysiology.

\section{Structure of the lipid droplets Phospholipid composition}

Being different from other membrane-enclosed organelles, LDs have a unique structure with a hydrophobic core of neutral lipids surrounded by a monolayer phospholipid membrane, separating hydrophobic neutral lipids from the aqueous cytoplasmic environment [21].. In the hydrophobic core of LDs, neutral lipids, predominantly TG and $\mathrm{SE}$, are stored at various ratios (Fig. 1). In white adipocytes, TG are primarily stored in LDs as lipid esters, whereas in steroidogenic cells, SE are the main components [22]. Also, depending on the cell type, many other endogenous neutral lipids such as retinyl esters, ether lipids, and free cholesterol are stored in LD cores [23-25]. Interestingly in some cell types, electron microscopy data revealed that membrane-like structures containing ribosomal units were also extending within the core of LDs [26, 27].

In mammalian cells, the main constituent (up to 60\%) of LD monolayer membranes is phosphatidylcholine (PC) that is followed in abundance by phosphatidylethanolamine (PE), phosphatidylinositol (PI), phosphatidylserine (PS), sphingomyelin (SM) and lyso forms of PC and PE [28-30]. Phosphatidic acid and free cholesterol are also present in LD surfaces in minor amounts [21,31].

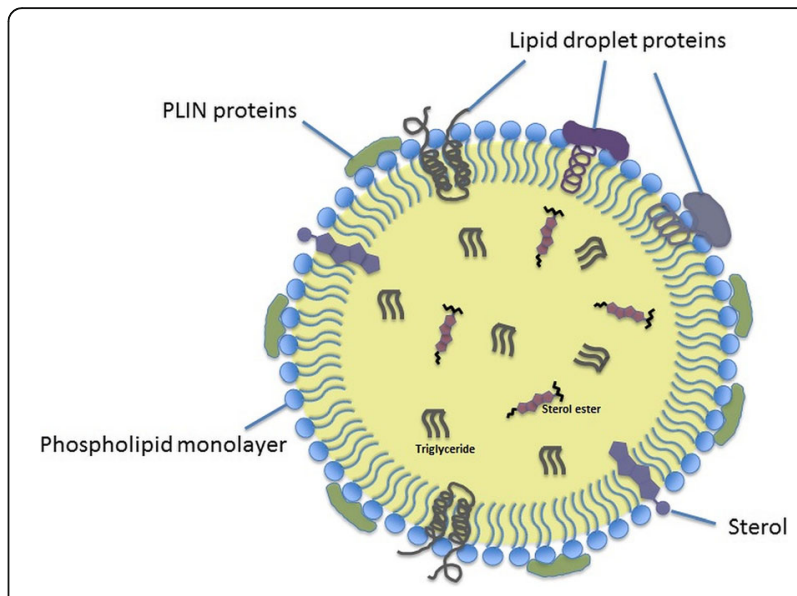

Fig. 1 Basic Morphology of Lipid Droplets

Although LD formation was believed to take place between the leaflets of endoplasmic reticulum (ER), phospholipid composition of LD membrane differs from that of ER and other organelles [21]. The unique phospholipid membrane composition primarily affects LD synthesis [32], maturation (size) [33, 34] and degradation via lipophagy mechanisms $[35,36]$. Changes in $\mathrm{LD}$ membrane phospholipid ratios under physiological conditions in various cell types indicate that regulation of phospholipid composition is crucial for homeostasis of this organelle.

\section{Surface protein structure}

Besides membrane phospholipid compositions, LD surface proteins are other factors regulating homeostasis and intracellular interactions of LDs. Membrane surface of LD is decorated with several structural and functional proteins [37]. Proteomics studies on LDs in a variety of organisms including bacteria [38-40], plants [41, 42], yeasts [43, 44], insects [45, 46] and mammals [47-49] revealed that over two hundred different proteins are localized to the surface of LDs. Even though LD proteomics studies that were performed in various cell types and organisms resulted in the discovery of different profiles, identified proteins seem to function in common pathways. These proteins were categorized into several distinct functional classes (Table 1).

In mammalian LDs, predominant proteins are the members of the PAT protein family, an acronym representing perilipin (PLIN), adipocyte differentiation-related protein (ADRP; also called as adipophilin), and TIP47 (tail-interacting protein of $47 \mathrm{kDa}$ ) proteins. Members of the PAT family share sequence similarity and the ability to bind intracellular LDs, suggesting that they derived from a common ancestral gene [50]. The most studied member of the PAT family is PLIN, a protein that regulates the access of lipases to neutral lipids in the core of 
Table 1 Classification of proteins located on the LD surface

\begin{tabular}{|c|c|c|c|}
\hline Protein Group & Short Name & Long Name & References \\
\hline \multirow[t]{3}{*}{ PAT Family } & PLIN & Perilipin & {$[49,160]$} \\
\hline & ADRP & Adipose differentiation-related protein & {$[24,27,48,161-163]$} \\
\hline & TIP47 & Tail-interacting protein of 47 kD & {$[48,160,163-165]$} \\
\hline \multirow[t]{19}{*}{ Lipid \& Energy Metabolism } & HSL & Hormone sensitive lipase & {$[49,160]$} \\
\hline & ATGL (PNPLA2) & Adipose triglyceride lipase & {$[24,162,166]$} \\
\hline & CGl-49 & CGI-49 protein & {$[24,27,48,49,165]$} \\
\hline & CGI-58 & CGl-58 protein & {$[24,27,49,160,162]$} \\
\hline & Mgll & Monoglyceride lipase & {$[97,163]$} \\
\hline & $\operatorname{Tgh}$ & Triacylglycerol hydrolase & [167] \\
\hline & LACS3-4 & Long-chain-fatty-acid-CoA ligase 3-4 & {$[24,48,49,162,165]$} \\
\hline & H105e3 & Sterol-4-carboxylate 3-dehydrogenase & {$[48,163-165]$} \\
\hline & SE & Squalene monooxygenase & {$[27,162,168]$} \\
\hline & Lss & Lanosterol synthase & {$[49,160,169]$} \\
\hline & Cpla2 & Cytosolic phospholipase A2 & {$[24,169,170]$} \\
\hline & Pcyt1a & Phosphocholine cytidylyltransferase A & {$[169,171,172]$} \\
\hline & Mdh2 & Malate dehydrogenase & {$[97,173,174]$} \\
\hline & Cyb5r3 & NADH-cytochrome b5 reductase & {$[24,49,162,173]$} \\
\hline & Dhrs1 & Dehydrogenase/reductase SDR member 1 & {$[24,49,162,173]$} \\
\hline & Dhrs3 & Short-chain dehydrogenase/reductase 3 & {$[92,169,173]$} \\
\hline & Nsdhl & NAD(P)H steroid dehydrogenase-like & {$[163,169,173]$} \\
\hline & Acsl1-3 & Long-chain acyl-CoA synthetase 1-3 & {$[24,49,175]$} \\
\hline & Ldah & LD-associated hydrolase & {$[173,176,177]$} \\
\hline \multirow[t]{3}{*}{ Signalling } & $\mathrm{CHP}$ & Calcium-binding protein p22 & {$[24,164,165,178]$} \\
\hline & Cav1 & Caveolin1 & {$[24,49,162]$} \\
\hline & METTL7A & Methyltransferase-like protein 7A & {$[92,174,178]$} \\
\hline \multirow[t]{10}{*}{ Membrane trafficking proteins } & VIM & Vimentin & {$[24,49,160,162,171]$} \\
\hline & ACTB & Actin, cytoplasmic 1/ $\square$-Actin & {$[24,27,163,165]$} \\
\hline & Rab10 & Ras-related protein Rab-10 & {$[24,27,48,162,165]$} \\
\hline & Rab 11A & Ras-related protein Rab-11A & {$[24,162,164]$} \\
\hline & Rab 1a & Ras-related protein Rab-1a & {$[24,162,164,165]$} \\
\hline & Rab 1b & Ras-related protein Rab-1b & {$[48,164,165]$} \\
\hline & Rab 14 & Ras-related protein Rab-14 & {$[24,49,160,162,164]$} \\
\hline & Rab 18 & Ras-related protein Rab-18 & {$[24,49,162,164,165]$} \\
\hline & $\operatorname{Rab} 5 b$ & Ras-related protein Rab-5b & {$[24,162,165,166]$} \\
\hline & Tubulin & Tubulin & {$[24,49,163,178]$} \\
\hline \multirow[t]{9}{*}{ Miscellaneous } & Stomatin & Stomatin & {$[162,165]$} \\
\hline & HSPA5 & 78 kDa glucose- regulated protein & {$[24,48,49,160,162-165]$} \\
\hline & Hspa1a & Heat shock $70 \mathrm{kDa}$ protein $1 \mathrm{~A}$ & {$[24,49,161]$} \\
\hline & FAF2 & FAS-associated factor 2 & {$[24,48,162,166]$} \\
\hline & Ancient ubiquitous protein BiP & Ancient ubiquitous protein BiP & {$[24,49,160,162,165,166]$} \\
\hline & CANX & Calnexin & [49] \\
\hline & HSP 70 & Heat shock protein 70 & {$[49,161,165]$} \\
\hline & Ribophorin I & Ribophorin I & {$[49,160]$} \\
\hline & ApoB & Apolipoprotein B & [174] \\
\hline
\end{tabular}


Table 1 Classification of proteins located on the LD surface (Continued)

$\begin{array}{lll}\text { a-synuclein } & \text { a-synuclein } & {[92]} \\ \text { Hepatitis C core protein } & \text { Hepatitis C core protein } & {[175-177]} \\ \text { His2A } & \text { Histone 2A } & {[89]} \\ \text { His2B } & \text { Histone 2B } & {[89]} \\ \text { Alb } & \text { Serum albumin } & {[27,161,163]}\end{array}$

LDs, hence controlling lipid homeostasis. Consistently, elevated basal lipolysis levels were observed in adipocytes obtained from PLIN knockout mice models [51].

LDs also host many other proteins-related to lipid homeostasis. These proteins can be classified according to their functions, including lipid biogenesis (long chain fatty acid CoA ligases, lanosterol synthase, squalene epoxidase), maintainance of intracellular lipid metabolism (long chain fatty acid CoA ligases) and lipid degradation (patatin-like phospholipase domain containing protein 2 (PNPLA2), CGI-58) [52].

In addition to PAT proteins and lipid homeostasis-related proteins in LDs, there are several groups of proteins that are called 'refugee proteins' which seem not to be relevant to the known functions of LDs [53]. These proteins are categorized as signaling proteins, membrane trafficking proteins, chaperons and proteins-associated with cellular organelles (Table 1). Signaling-related proteins are classes of proteins that accumulate on the surface of LDs. Major signalling proteins such as, mitogen-activated protein kinase (MAPK), phosphatidylinositol 3-kinase (PI3K) and Lyn proteins have been shown to localize on LD surfaces $[54,55]$. Moreover, caveolins are another group of LD proteins that specifically form a coat by making invaginations and surrounding cellular membranes called caveolae. Caveolae function in endocytosis, signal transduction, cholesterol transport and growth control [33, 56, 57]. Caveolin-1 and caveolin- 2 proteins were shown to reside on the surface of LDs. They generate membrane domains where they function as regulators of signaling proteins $[58,59]$. Discovery of membrane trafficking proteins on the surface of LDs and the fact that interact with other cellular compartments through intarcellular motility, suggest that LDs are distinct organelles. Membrane trafficking-related proteins consist of five subgroup proteins: Small GTPases governing vesicle formation and motility; motor proteins such as kinesin and myosin that carry LDs on the cytoskeleton; soluble NSF attachment receptor (SNARE) proteins mediate membrane docking and fusion on LDs; vesicular traffic proteins (such as ARFs and COPs) that regulate cargo sorting and vesicle budding; and other membrane trafficking proteins of miscellaneous functions [4].

\section{LD Biogenesis}

LD biogenesis is stimulated upon an increase in intracellular free FA levels. In order to prevent lipotoxicity, excessive free fatty acids are converted into neutral lipids and stored in cytosolic LDs. However, recent studies suggested that LDs are not only cytoplasmic but also can be found in the nuclei $[60,61]$. Although the morphology of these 'nuclear LDs' is similar to their cytoplasmic counterparts, their biogenesis mechanisms remain unexplained. Nuclear LDs are thought to regulate nuclear lipid homeostasis and modulate signaling through lipid molecules [3].

Due to the unique hydrophobic/hydrophilic (amphipathic) structure of LDs, mechanisms of biogenesis of this organelle in the cell attracted much attention and several hypotheses were proposed [62-64]. Being different from most self-replicating organelles, LDs are mainly formed de novo. In addition, LDs could be derived via fission of pre-existing LDs [65]. In prokaryotes, neutral lipid accumulation seems to be initiated at specific lipid domains of plasma membrane and ends in the formation of cytoplasmic LDs [62]. On the other hand, as a eukaryotic LD biogenesis mechanism, there is evidence that LD formation occurs within the leaflets of ER phospholipid bilayer in discrete steps involving neutral lipid synthesis, progressive neutral lipid accumulation in the ER and cytosolic droplet formation. Increased volume of accumulated neutral lipid between the ER bilayer exceeds the solubility limits and LDs are thought to be 'oiled out' from the ER bilayer [66]. Consistent with the hypothesis, many electron microscopy studies in various cell types showed that cytosolic LDs are tightly associated with ER [67, 68] (Fig. 2).

\section{Neutral lipid synthesis}

Neutral lipid synthesis is regulated by complex pathways involving lipid metabolism enzymes and structural proteins that are permanently or transiently located to the ER and LDs. The first step of neutral lipid synthesis requires free FA activation. As free FA are chemically inert, their activation step is critical for LD biogenesis pathway. In mammalian cells, acyl-coA synthetase (ACS) enzymes activate long chain FAs to acyl-coA by esterifying with coenzyme A (CoA) (Fig. 2a) [69]. De novo TAG synthesis occurs in a four-step pathway involving glycerol3-phosphate O-acyltransferase (GPAT), 1-acylglycerol-3phosphate O-acyltransferase (AGPAT), phosphatidic acid phosphatase (PAP) (or lipin), and diacylglycerol acyltransferase (DGAT) enzymes. At the last step of the pathway, 


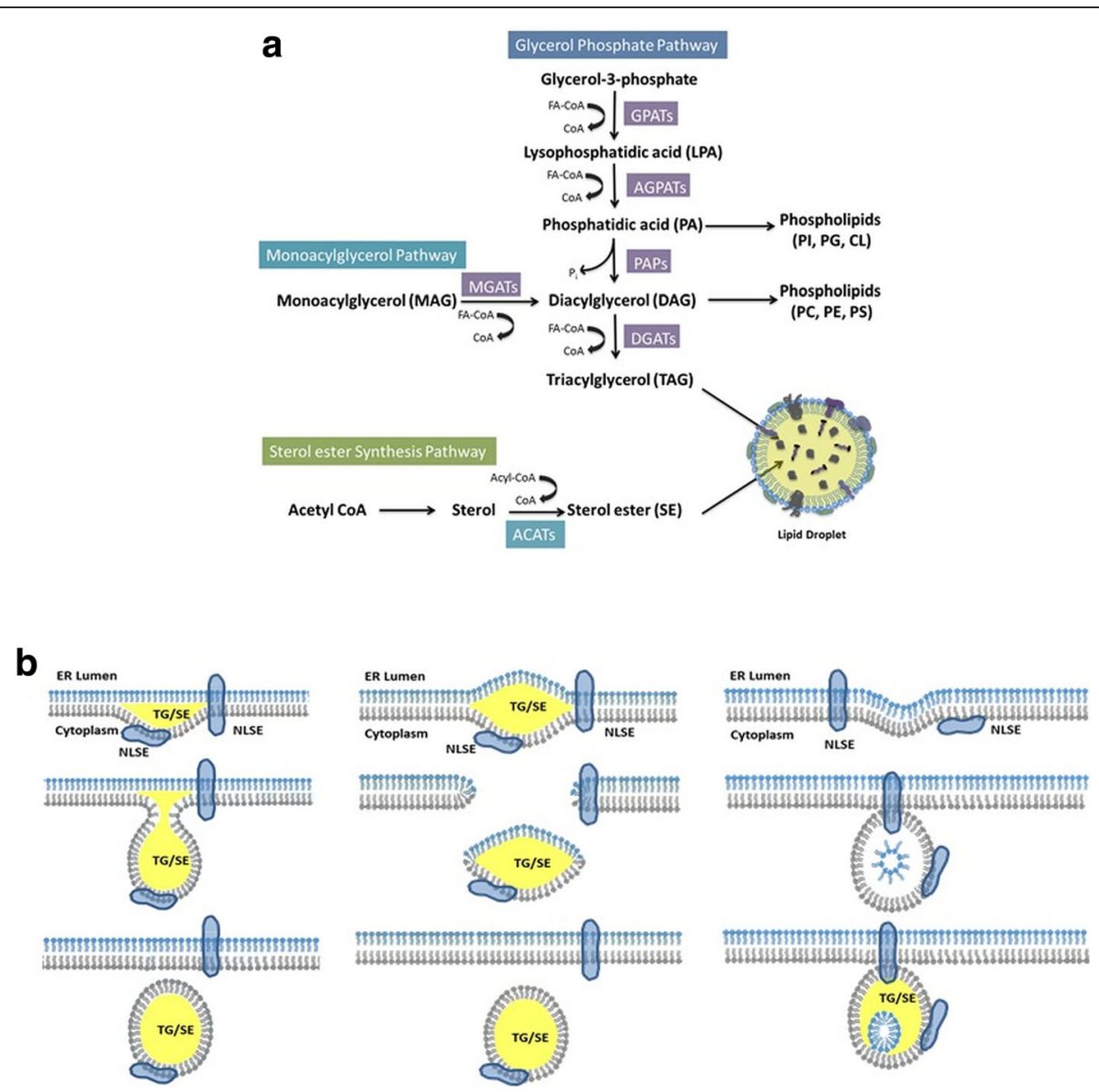

Fig. 2 Neutral Lipid Synthesis, Lipid Droplet (LD) Formation and Growth. a Metabolic pathway of triglyceride (TG) and sterol ester (SE) synthesis, b LD Formation from Endoplasmic Retikulum (ER) by Neutral Lipid Synthesis Enzymes (NLSE). Left panel shows budding model of LDs from ER; middle panel shows bicelle formation model of LDs originating from ER; right panel shows hatching model of LDs from ER

FAs, firstly activated to acyl-CoA, are converted to TAGs through DGAT1 and DGAT2 enzymes in mammalian cells. In addition, some LDs store mainly sterol esters (SE) specifically in macrophages, adrenocortical cells, ovarian and testicular interstitial cells. The synthesis of SE is conducted by acyl-CoA cholesterol O-acyltransferases (ACAT1 and ACAT2). The neutral lipid biosynthesis enzymes DGAT1, ACAT1, and ACAT2 were shown to localize on ER domains in mammalian cells [70-72].

\section{LD Formation from $E R$}

As intracellular FA promote LD formation, synthesized neutral lipids form a 'lens' between the leaflets of ER bilayer. Biophysical and in silico predictions suggest that, when TG holding limit of bilayer membranes is reached [23], the lens between ER bilayers is 'oiled out' and leads to the formation of nascent LDs. However, it is still an open question how phospholipid monolayer membrane of LDs is derived from ER bilayer membranes. Walther et al. claimed two models about LDs leaving ER membranes (Fig. 2b) [10]. The most widely accepted model states that neutral lipid lens buds out from the ER together with the outer leaflet of the bilayer membrane. This process is thought to be drived by structural LD associated proteins such as PAT proteins in a way that PAT proteins could mediate budding at specific domains of ER bilayer membrane [10]. Their suggested second model states that LDs are excised from both leaflets of the ER membrane bilayer as a bicelle (a lipid monolayer vesicle formed by the fusion of the tips of the outer and inner membranes of the ER with accumulated lipid lens within) [10]. In addition to these models, Fujimoto et al. suggested that LDs are excised from 'both leaflets of the ER membrane bilayer as a bicelle' by hatching mechanism (bilayer budding and monolayer membrane formation because of micelle-like isolation of the inner membrane leaflet in the LD lumen) (Fig. 2b) [22]. Although neither of these models rely on solid data, they could hypothetically explain how hydrophobic cores of LDs are surrounded by phospholipid monolayer membranes that are derived from ER membranes and how some ER membrane proteins are targeted to newly formed LDs. 


\section{Growth of lipid droplets: the size matters}

Once LDs are synthesized, they typically keep growing because of the excessive amount of intracellular FA in cells and reach a final size. The size of LDs varies within a wide range $(0.4-100 \mu \mathrm{m})$ in different cell types [73]. Even in the same cell, the size of LDs may dramatically differ under changing pathophysiological conditions. Recent studies have shown that subpopulations of LDs may differ in terms of size, morphology, and function within the same cell $[74,75]$. Many proteins (e.g. Fsp27, seipin, FITM2 and perilipin1) and lipid factors (e.g. phosphatidylcholine and phosphatidic acid) have been shown to be involved in LD growth mechanisms [73].

One possible mechanism is growth of LDs through fusion of highly mobile smaller LDs [76, 77]. Although there is conspicuous skepticism in the literature, LD fusion rates are high enough to allow LD growth [78], RNAi knockdown of fusion mediator SNARE proteins prominently decreased fusion rates and size of LDs [76]. In addition, mutant form of the yeast homologue of seipin in the mammals regulates phosphatidic acid metabolism and leads to 'supersized LDs' by enhancing coalescence of them [31]. Similarly, knockdown of phosphocholine cytidylyltransferase (CCT) enzymes, catalyzing the rate limiting step of phosphatidylcholine synthesis, dramatically induce fusion of LDs, balance surface volume ratio and regulate LD size [79]. Another possible mechanism for growth of droplets is the lateral transfer of synthesized neutral lipids from ER to LDs. If nascent LDs remain attached to ER, as neutral lipid synthesis enzymes on the bilayer membrane of the ER convert FA to neutral lipids, these molecule may be transferred to adjacent LDs [1]. Similar to this mechanism, Gong et al. stated that lipid droplet growth occurs by lipid transfer at LD contact sites between adjacent LDs via Fsp27 (Fat specific protein-27 or cell deathinducing DFF45-like effector C (Cidec)) protein [80]. Ectopic expression of Fsp27 protein promotes formation of unilocular large LDs through stimulation of TG accumulation [80-82]. Alternatively, Fujimoto et al. suggested that neutral lipid synthesis occurs on the surface of LDs [83]. Since phospholipid monolayers of LDs are derived from ER membranes, neutral lipid synthesis enzymes originating from these membranes could be directly transfered to the surface of LDs. Particularly, during lipid loading, DGAT2 enzymes which normally localize to the ER, were shown to localize on the surface of LDs [71, 84]. However, it is ambiguous whether earlier steps of neutral lipid synthesis also take place on the surface of LDs.

\section{Function of LDs other then lipid storage}

Interestingly, LDs were involved in various pathological events and innate immunity [85]. LDs were shown to be targeted by various pathogens including viruses, bacteria and parasites. Hepatitis $\mathrm{C}$ virus (HCV) was appeared to use the LDs for proliferation and assembly of capsid proteins were shown to take place in the vicinity of host LDs [86]. In addition to $\mathrm{HCV}$, many viruses including GB virus $B$ and dengue virus (DENV) also hijack LDs for viral replication $[87,88]$. As LDs may also be related to the pathogenesis of hepatic steatosis caused by viral infections and from this perspective, LDs may become a theurapetic target [22]. Furthermore, LDs may serve in the cytoplasmic sequesteration of proteins such as histones and $\alpha$-synuclein $[37,52]$. In Drosophila embryos, histones are found in high abundance on the surface of LDs and they are rapidly transferred to the nucleus when needed [89]. Recently, histone storage function of LDs was also defined as a defense mechanism against pathogens. Indeed, histones around LDs were shown to possess bactericidal activity [3]. Neuropathological protein aggregates of $\alpha$-synuclein and amyloid $\beta$ peptide were shown to be in a close proximity with cytosolic LDs in various cell types [90-92]. In addition, recently Moldavski et al. stated that LDs play important roles as clearing mechanisms of inclusion bodies in cells [93]. Protein sequestration role of LDs may explain the presence of 'refugee proteins' that are found associated with LDs, and provide a dynamic regulatory mechanism for protein storage and degradation [53].

\section{The catabolic pathways of LDs}

As the LDs reside at the center of cellular lipid and energy homeostasis, their catabolism is strictly under the control of hormones and activation of enzymes. So far, LDs are known to break down mostly by lipolysis, however, recent discoveries that showed a molecular connection between lipolysis and autophagy mechanisms led to the identification of the involvement of selective autophagic forms, lipophagy and CMA, in LD catabolism.

\section{Lipolytic hydrolysis}

Under fed conditions, LDs store TAGs mainly in adipose tissues and hydrolysis of ester bonds between long chain FAs and glycerol backbone in TAGs is called "lipolysis". During the first step of lipolysis, protein kinase A (PKA) phosphorylates one of the PAT protein family member, PLIN1, and leads to its proteasomal degradation [94]. This, results in the release of ATGL activator protein CGI-58, which then initiates TAG breakdown via activated ATGL $[95,96]$. ATGL selectively catalyzes the first step of TAG hydrolysis to generate diacylglycerols (DAGs) and free FAs [97]. The second step of lipolysis is depend on the activation of hormone sensitive lipase (HSL) which is a multifunctional enzyme that is capable of hydrolyzing both the first and the second step of lipolysis. HSL hydrolyzes DAGs and produce monoacylglycerol 
(MAG) and FAs [98]. Within the lipolysis cascade, HSL functions as a rate-limiting enzyme for DAG catabolism $[99,100]$. In the last step of lipolysis, MAGs are released into the cytosol and eventually cleaved by MGL to generate glycerol and FA [101] (Fig. 3).

Under nutrient deprivation, products of lipolysis are secreted from the adipose tissue to the periphery via bloodstream, which are then used for $\beta$-oxidation and ATP production. In contrast, in non-adipose tissues, mitochondria or peroxisomes can directly oxidize products of lipolysis through $\beta$-oxidation and release acetylCoA [102].

\section{Lipophagy}

Lipophagy was first described in mouse hepatocytes under starvation [103]. It was shown that LDs were mobilized in order to generate free FAs. Pharmacological or genetic inhibiton of lipophagy resulted in elevated TAG concentrations, increasing concomitantly LD numbers and size. Electron microscopy data confirmed sequesteration of LDs by double-membraned autophagosomes that labeled positive with the autophagy marker LC3 (Microtubule-Associated Proteins 1A and 1B, Light Chain 3). Intriguingly, LC3 as well as PLIN1 and PLIN2 proteins were found in LDs and lysosomes that were isolated from starved livers. In addition, LDs were shown to colocalize with lysosomes, indicating a role for lysosomes in lipid turnover via LDs break down [103]. LDs were shown to be selectively engulfed by a autophagosomes that was followed by the fusion of autophagosomes with lysosomes (autolysosomes) for degradation. Therefore, lipophagy is an LD-selective type of macroautophagy. In line with that, inhibition of the small GTPase dynamin-2 caused the accumulation of LDs in autolysosomes [104] (Fig. 4a).

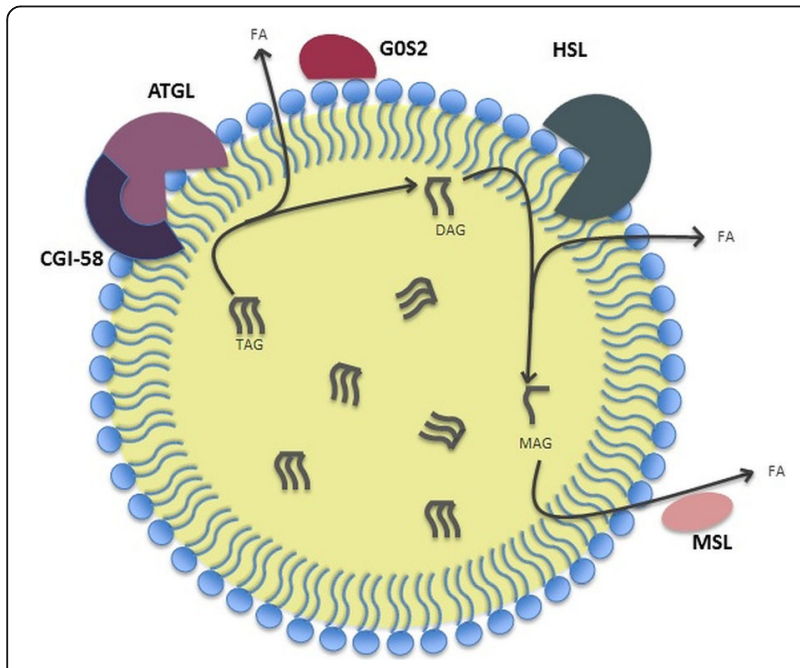

Fig. 3 Lipolysis of Lipid Droplets
Substrate labeling is a general mechanism used by cellular degradation machineries. So, how does lipophagic machinery preferentially recognize LDs as substrates? Proteomic analyses of LDs from different organisms showed that membrane GTPase Rab7 is associated with LDs and suggested a universal role of Rab7 in the regulation of LD docking and degradation [105]. Involvement of GTPases in endosome-autophagosome interactions [106] is made Rab7 a strong candidate for selection of LDs as lipophagic substrate. Activation of lipophagy in starved hepatocellular cells lead to significant increase in Rab7-LD association while Rab7 mutants, defective in binding to Rab7-interacting lysosomal protein (RILP) failed to promote lipophagy [18]. Furthermore, starvationactivated Rab7 was shown to lead to the recruitment of multivesicular bodies to the LD-autophagosome complex and induced the formation of amphisomes through fusion of autophagosomes and endosomes [18]. In this study, microscopy data revealed an interaction between LDs, autophagosomes and lysosomes, which is consistent with the concept that LDs do not fuse directly with lysosomes [103]. In addition to hepatocytes, the essential role of Rab7 for autolysosome-mediated LD degradation during hormone-stimulated lipophagy was also shown in adipocyte cells. In these cells, LD-associated PLIN1 protein inhibited lipophagy by blocking Rab7 binding to the LD surface [18]. Consequently, Rab7 was identified as a protein regulating LD docking via its effector protein RILP and FYVE and coiled-coil domains containing protein 1 (FYCO1) that directly connects the cargo to LC3 proteins on autophagosome membranes [18].

In adipocytes, the membrane curvature protein Bif-1 was found as a novel regulator protein for lipophagy [107]. Induction of lipophagy has been shown to promote Bif-1-dependent degradation of LD-associated PLIN1, and deficiency of this protein led to decreased TAG hydrolysis, indicating that Bif- 1 is essential for lipophagy-dependent PLIN1 degradation, and thereby LD break down [107]. Note that, membrane curvature varies according to LD size, however, whether Bif-1 affects LD targeting by lipophagy through its effects on LD size, is still unknown.

Although the role of lipophagy in LD degradation was first described in hepatocytes [103, 108], several recent studies shown activation of this mechanism in various cell types, such as neurons [109, 110], glial cells [109], foam cells [111], enterocytes [112], T cells [113], fibroblasts, adipocytes [114] and prostate carcinoma cells [115]. Moreover, lipophagy was demonstrated in yeast [116], C. elegans [117] and some fungus species [118]. Indeed, mechanisms that trigger lipophagy may vary in each cell type, and it could be context-dependent. It is likely that cells adapted lipophagy mechanisms in order to better deal with extreme conditons, such as 


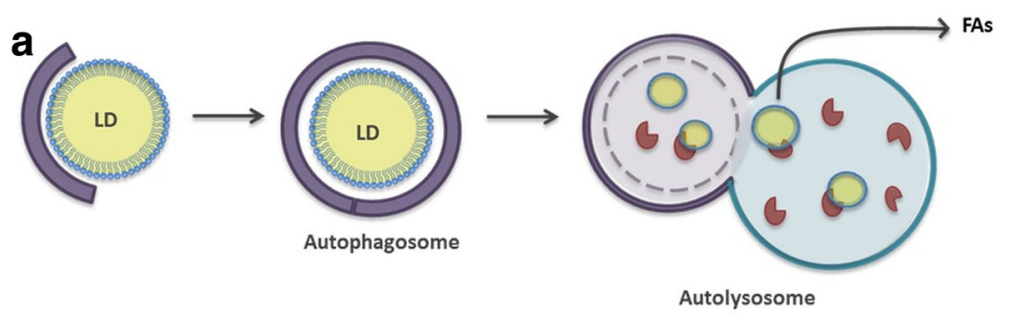

b

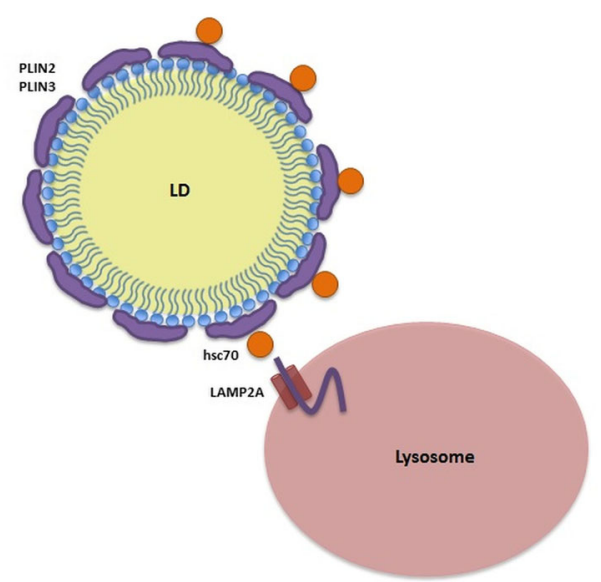

Fig. 4 Lipid Droplet Degradation by Autophagy Mechanisms. a Lipophagy b Chaperone Mediated Autophagy (CMA)-dependent degradation

lipotoxicity, nutrient deprivation etc. However, the core components that are essential for lipophagy seem to be conserved in most cell types.

\section{Chaperone-mediated autophagy (CMA)}

More recently, involvement of another selective type of autophagy, CMA, in degradation of LD-associated PLINs proteins, PLIN2 and PLIN3 was described [19]. In this context, activation of CMA was shown to induce PLIN2 and PLIN3 turnover, which caused recruitment of ATGL and lipophagic protein ATG, leading to the degradation of LDs. Consistantly, inhibiton of PLINs degradation in CMA-deficient model systems, resulted in both reduced ATGL recruitment, and lipophagy activation gave rise to LD accumulation. Therefore, functional CMA was shown to be essential for the removal of LD-associated proteins, which in turn led to the accumulation of lipases and lipophagy proteins on specific regions of LDs [19] (Fig. 4b).

\section{Cross-talk between lipolysis and lipophagy/CMA mechanisms}

Even though basic molecular mechanisms of lipolysis, lipophagy and CMA are different, recent investigations indicate that these independent pathways actually crosstalk. For example, ATG2A, an essential autophagy protein was also found on LDs, and genetic knock-down of ATG2A and ATG2B resulted in defective lipophagy as well as LD accumulation [119]. A recent study with starved mouse embryonic fibroblasts (MEF) demonstrated that FAs derived from LDs end-up in mitochondria which is required only for ATGL-dependent lipolysis activation not for lipophagy [120]. In the same study, size and number of LDs increased as result of autophagic degradation of other cellular membrane components, confirming that overall lipid content that recycled via autophagy, contributed to the growth of LDs. As mentioned before, Bif-1 regulating curvature of various membranes including autophagic membranes, was identified as a protein involved in lipophagy regulation in adipose tissues [107]. PLIN2 and PLIN3 are CMA substrates, and they contribute to the cross-talk between lipolysis and CMA. Promotion of ATGL and lipophagy proteins by CMA activation was shown to trigger not only lipophagy but also lipolysis, indicating that PLIN2 and PLIN3 undergo CMA-mediated degradation before the initiation of lipolysis [19]. Moreover, lipolysis has been shown to depend on PLIN2 phosphorylation by AMPK, which occured after the interaction of PLIN2 with CMA chaperone protein Hsc70 [20]. A complex cross-talk between lipolysis and lipophagy has been described in brown adipose tissue, in which both central nervous system (CNS) and local cytosolic lipases were involved. Here, the autophagosome marker LC3 recruited ATGL and HSL to LDs, supporting coordinated regulation of 
lipolysis by both CNS and peripheral protein-protein interactions [121].

On the other hand, the existance of a reverse relationship between lipolysis and lipophagy has also been shown in which lipolysis-dependent LDs breakdown regulated autophagosome formation. LDs was shown in close proximity of autophagosomes with transient 'kiss and run' interactions contributing to autophagosome biogenesis [122]. In this process, patatin-like phospholipase domain containing protein-5 (PNPLA5), a lipase localized on the surface of LDs, was shown to be needed for optimal initiation of autophagosome formation by generating DAG, a building block for phospholipid constituents of the double-membrane structure [122]. Consistent with this, additional evidence has been provided by a yeast study, demonstrating that deletion of TAG and SE synthesis enzymes resulted in the inhibition lipophagy [123]. In a very recent yeast study, absence of LDs caused morphological changes in the ER due to defective FA synthesis, compromised autophagosome biogenesis [124]. Therefore, active lipolysis on the LD surface or LD-ER contact sites is required for the de novo formation of autophagosomes [122-124].

\section{Pathophysiological relevance of lipolysis, lipophagy and CMA}

As LDs play central role in the regulation of intracellular lipid and energy metabolism, abnormalities of LDrelated mechanisms, including lipolysis, lipophagy and CMA are involved in many pathological and physiological conditions. For example, neutral lipid storage disease (NLSD), atherosclerosis, obesity etc. [8, 125].

\section{Neutral lipid storage disease (NLSD)}

Neutral Lipid Storage Disease (NLSD) is a heterogenous group of rare autosomal recessive disorder characterized by abnormal accumulation of LDs in multiple tissues and lymphocytes. Mutations in one of the two genes coding for ATGL or CGI-58 (proteins located on the surface of LDs) are associated with the NLSD [126, 127]. Both ATGL and CGI-58 coordinately function in the lipolysis of LDs; however, mutations in each gene result in different symptoms. Mutations in CGI-58 (a coactivator of ATGL), are associated with NLSD with ichthyosis known as Chanarin-Dorfmann syndrome (CDS) characterized by defective permeability barrier of the skin [128-130]; whereas, ATGL mutations lead to severe NLSD with cardiac myopathy (NLDSM) [131]. These symptomatic differences may be related to the different functions of CGI-58 independent from ATGL. For example, CGI-58 was shown to have acyltransferase activity in phosphatidic acid biosynthesis and play an ATGL-independent role in the phospholipid metabolism [132]. It was suggested that, apart from its lipolytic activity, CGI-58 may facilitate the utilization of hydrolysis products of TGs as phospholipids, and maintain TG homeostasis [132].

\section{Obesity}

Obesity is a common health problem, which is characterized by excessive lipid storage in various cell types such as adipocytes, muscle cells and hepatocytes. Different types and degrees of obesity were shown to be directly related with the lipophagic activity of cells and the size of their lipid storages [133]. Additionally, lipophagic activity was found to be upregulated in the adipose tissue of obese people, and especially in those who have particularly high intra-abdominal fat accumulation. In these people, visceral lipid distribution or hypertrophic adipocytes could also be seen concomitantly with insulin resistance [134]. Under these conditons, upregulation of lipophagy might protect cells against lipotoxicity by clearing excessive intracellular lipids, and decrease obesity-dependent mortaility in patients [134]. In fact, the amplitude of lipophagic activation may depend on the metabolic properties of individuals. For example, in patients diagnosed with type- 2 diabetes which is characterized by insulin resistance, inhibition of the main energy regulator pathway, mTOR, was described as the responsible mechanism for lipophagic upregulation [135]. Yet, enhanced LD formation can sometimes lead to excessive release of FAs from LDs, and lipophagy may favor intracellular lipotoxicity under these conditons [135].

Accumulation of LDs in tissues in high amounts may cause chronic inflammation which is identified as one of the hallmarks of obesity-related metabolic disorders. Indeed, enlarged LDs in the adipose tissue may lead to cellular remodeling, and finally lead to macrophagedriven chronic inflammation [136]. Activation of macrophages is a energy-dependent mechanism and relies on FA oxidation, suggesting a possible involvement of lipophagy in this mechanism. Accordingly, lipophagy was shown to increase with obesity in adipose tissue macrophages; however, their activation was not affected, suggesting that lipophagy only regulates elavated intracellular lipid level in the adipose tissue [114]. Liu et al. have shown decreased level of lipophagy with obesity in hepatic macrophages, and inhibiton of lipophagy was shown to favor the immune responses by promoting proinflammatory macrophage activation [137]. Very recently, lipophagy was found as an essential catabolic mechanism in adipose tissue macrophages, and it increased with obesity. But intriguingly, genetic or pharmacological inhibition of lipophagy did not change lipid balance, indicating existence of another pathway critical to lysosome TG hydrolysis [138]. All these data indicate that the role of lipophagy in 
macrophage-driven inflammation may depend on metabolic conditions of obesity or inflammatory stimulus.

\section{Fatty liver diseases}

The important role of lipophagy regarding LD breakdown in hepatocytes suggests that impaired lipophagy may contribute to the development of steatotic liver diseases such as non-alcoholic and alcoholic steatohepatitis [133]. These diseases are characterized by increased level of lipid storage in LDs, and they progressively lead to the development of chronic liver injury and its complications, such as fibrosis and hepatocellular cancer $[139,140]$.

Promotion of lipophagy by resveratrol treatment was shown to attenuate methionine choline-induced nonalcoholic steatohepatitis [141]. Consistently, in a recent study, lipophagy has been found to play an important protective role in methionine choline-induced nonalcoholic steatohepatitis [142]. Lipophagy has also an important protective role in acute alcohol-induced hepatic steatosis and injury [143]. Likewise, impairment of both non-selective macroautophagy and selective CMA promoted oxidant-induced liver injury, indicating that oxidative stress resistance and liver injury is connected to autophagic activity [144]. Another report also support the protective role of lipophagy against chronic alcoholinduced hepatotoxicity caused by oxidative stress [145].

Liver fibrosis may be the first step of more serious cirrhotic liver conditions. Hepatic stellate cells (HSCs) activation for the development of this condition, and lipophagy plays a role as well $[146,147]$. HSCs are quiescent cells having large lipid stores that are metabolized during activation. Increased lipophagy was shown in HSCs upon fibrotic stimuli and HSC-specific inhibiton of lipophagy blocked their activation, leading to improved liver fibrosis in mice and in human tissues [147]. On the other hand, controversy exist over the effect of lipophagy modulation in this disease. For example, pharmacological induction of lipophagy was shown to be a promissing treatment for liver fibrosis in alpha-1 antitrypsin deficiency [148]. Even though HSCs activation is a common phenomenon for fibrogenesis among tissues, whether lipophagy mediates fibrosis in other organs is still unknown.

Today, it is well known that after many years of chronic non-alcoholic or alcoholic steatotic liver diseases or hepatitis virus infection hepatocellular carcinoma (HCC) might develop. Hepatitis B virus (HBV) and hepatitis $\mathrm{C}$ virus (HCV) replication was shown to be induced by autophagy activation both in vitro and in vivo studies $[149,150]$. A number of reviews have described the role of non-selective and/or selective autophagy in $\mathrm{HCC}$, and accumulating data indicate changes of autophagic responses in this disease [133, 151]. However, there are discrepancies among studies that were published so far, and development of autophagy-based novel therapeutic strategies for HCC require further studies.

\section{Cholesterol ester storage disease (CESD)}

Cholesterol ester storage disease (CESD) is an autosomal recessive genetic disease caused by the mutation of the LIPA gene encoding lysosomal acid lipases (LAL). Deficient LAL activity lead to insufficient lipolysis and eventually intracellular accumulation of cholesterol ester and TGs [152]. The most severe form of CESD is identified as Wolman Disease that mostly presents in infancy and mainly result in infant fatality. Affected cells are characterized by the presence of lysosomes that are filled with excessive LDs and cholesterol clumps [153]. The involvement of lipophagy was shown in a study analyzed LD mobilization in macrophages [111]. LDs are the major organelles for cholesterol storage and the study demonstrated that cholesterol efflux from macrophage foam cells was regulated by lipophagy, which rely on LAL function. In line with these results, genetic knockdown of lipophagy in macrophages or knockout in the whole mice resulted in insufficient clearance of cholesterol in cells and tissues [111].

\section{Atherosclerosis}

Accumulation of cholesterol in macrophage foam cells also contribute to another common disease, atherosclerosis. The main cause of the disease is the accumulation of excessive cholesterol in arterial walls eventually leading to heart failure, stroke and cardiac dysfunction. Excessive cholesterol is esterified by ACAT enzymes and stored as cholesterolester (CE) in LDs of macrophages. Studies revealed that LD-associated proteins ACAT1 and ABCA1 regulating cholesterol esterification play crucial roles in atherosclerosis. In hyperlipidemic mice, deletion of ACAT1 results in both impairment of ABCA1 dependent cholesterol efflux and elevated atherosclerosis [154]. Moreover, among the PAT protein family of LDs, adipose differentiation-related protein (ADFP) was strongly associated with foam cell formation and atherosclerosis $[155,156]$.

The importance of lipophagic activation in controlling intracellular LDs level and the recent finding that lipophagy contribute LD mobilization in macrophages provides a new point of view in the pathogenesis of atherosclerosis. In addition to the dysfunction of above mentioned LD-associated proteins, it is likely that defective lipophagy may compromise the chronic exposure to excessive circulating lipids of the artery wall macrophages and may result in their remodelling into "foam cells". However, the significance of insufficient lipophagy underlying foam cell formation or progression is still not known. On the other hand, in a recent study on the tumor- 
supressor gene programmed cell death 4 (PDCD4), it was demonstrated that the protein inhibited autophagy in macrophages, and $P d c d 4$ knockout mice displayed increased atherosclerosis, indicating a link between autophagy and atherogenesis [157].

\section{Lipodystrophies}

Apart from excessive accumulation of lipids, deficiency of LDs in cells may lead to lipodystrophies. Particularly, defects in the synthesis of neutral lipids lead to deficiencies in LD formation and lead to the formation of abnormal or degenerative white adipose tissue. Genetic causes of lipodystrophies include various genes encoding proteins related to LD synthesis, storage and regulation such as acylglycerol-phosphate acyltransferase (AGPAT2), seipin (BCSL2) and caveolin (CAV1). In addition, lamin $\mathrm{A} / \mathrm{C}$ $(L M N A)$, peroxisome proliferator-activated receptor- $\gamma$ (PPARG), Akt2/protein kinase B (AKT2), and endoprotease Face-1 (ZMPSTE24) were identified as defective genes in partial lipodystrophies [158]. Insufficient LD biosynthesis in adipose tissue often leads to massive hepatic steatosis with subsequent metabolic abnormalities, including insulin resistance, diabetes, and hypertension [159].

\section{Conclusion}

In recent years, except the neutral lipid storage function of LDs, understanding of their various metabolic roles and intracellular interactions with many compartments makes this field as an attractive research area. Novel findings in selective types of autophagy, lipophagy and CMA, also contributed to a better of understanding of intracellular catabolic pathways regulating LDs. More importantly, signals that madiate the crosstalk between lipolysis and lipophagy lead to the consideration of these mechanisms as promising therapeutic targets. However there are a large number of questions that still need to be answered. Particularly, the pathophysiological relevance of LDs and their catabolic mechanisms must be further examined in order to discover potential therapies for common metabolic diseases such as obesity or atherosclerosis.

\footnotetext{
Abbreviations

ACS: Acyl-coA synthetase; ADFP: Adipose differentiation-related protein; ADRP: Adipocyte differentiation-related protein; AGPAT: 1-acylglycerol-3phosphate O-acyltransferase; AKT2: Akt2/protein kinase B; ATGL: Adipose triglyceride lipase; BCSL2: Seipin; CAV1: Caveolin; CCT: Phosphocholine cytidylyltransferase; CESD: Cholesterol ester storage disease; CGI58: Comperative gene identification-58; Cidec: Cell death-inducing DFF45-like effector C; CMA: Chaperone mediated autophagy; DAG: Diacylglycerols; DENV: Dengue virus; DGAT: diacylglycerol acyltransferase; ER: Endoplasmic reticulum; Fsp27: Fat specific protein-27; FYCO1: FYVE and coiled-coil domains containing protein 1; GPAT: Glycerol-3-phosphate O-acyltransferase; HBV: Hepatitis B virus; HCC: Hepatocellular carcinoma; HCV: Hepatitis C virus; Hsc70: Heat shock cognate 70; HSL: Hormone sensitive lipase; LAL: Lysosomal acid lipases; LAMP2a: Lysosomal-associated protein 2a; LC3: Microtubule-Associated Proteins 1 A and 1B, Light Chain 3; LD: Lipid droplet; LMNA: Lamin A/C; MAG: Monoacylglycerol; MAPK: Mitogen-activated protein kinase; MEF: Mouse embryonic fibroblasts; MGL: Monoglyceride
}

lipase; NLDS: Neutral lipid storage disease; NLDSM: NLSD with cardiac myopathy; PAP: phosphatidic acid phosphatase; PC: Phosphatidylcholine; PDCD4: Programmed cell death 4; PE: Phosphatidylethanolamine; PI: Phosphatidylinositol; PI3K: Phosphatidylinositol 3-kinase; PKA: Protein kinase A; PLIN: Perilipin; PNPLA2: Patatin-like phospholipase domain containing protein 2; PPARG: peroxisome proliferator-activated receptor- $\gamma_{\text {; }}$ PS: Phosphatidylserine; RILP: Rab7-interacting lysosomal protein; SE: Sterol ester; SM: Sphingomyelin; SNARE: Soluble NSF attachment receptor; TAG: Triacylglyceride; TIP47: Tail-interacting protein of 47 kDa; ZMPSTE24: Endoprotease Face-1

\section{Acknowledgements}

Not applicable.

\section{Funding}

This work is supported by Hacettepe University Scientific Research Projects Coordination Unit (Project number 014 D04 101,019-546). G.O is supported by The Scientific and Technological Research Council of Turkey (TUBITAK)BIDEB 2211, as scholarship student for her PhD study.

\section{Availability of data and materials}

Not applicable.

\section{Authors' contributions}

All authors made contribution in writing the manuscript. All authors read and approved the final manuscript.

\section{Author's information}

D.G. is a recipient of the Turkish Academy of Sciences (TUBA) GEBIP Award, EMBO Strategical Development and Installation Grant (EMBO-SDIG), IKU Prof. Dr. Onder Oztunali Science Award and TGC Sedat Simavi Award. D.G and O.K. are recipient of 2015 Elginkan Foundation Technology Research Award.

\section{Competing interests}

The authors declare that they have no competing interests.

Consent for publication

Not applicable.

Ethics approval and consent to participate

Not applicable.

\section{Publisher's Note}

Springer Nature remains neutral with regard to jurisdictional claims in published maps and institutional affiliations.

\section{Author details \\ ${ }^{1}$ Department of Medical Biology, Hacettepe University, 06100 Ankara, Turkey. ${ }^{2}$ Nanotechnology Research and Application Center (SUNUM) \& Center of Excellence for Functional Surfaces and Interfaces for Nano Diagnostics (EFSUN), Sabanci University, 34956 Istanbul, Turkey. ${ }^{3}$ Molecular Biology, Genetics, and Bioengineering Program \& Center of Excellence for Functional Surfaces and Interfaces for Nano Diagnostics (EFSUN), Sabanci University, 34956 Istanbul, Turkey.}

Received: 3 May 2017 Accepted: 16 June 2017

Published online: 29 June 2017

References

1. Thiele C, Spandl J. Cell biology of lipid droplets. Curr Opin Cell Biol. 2008;20:378-85.

2. Greenberg AS, Egan JJ, Wek SA, Garty NB, Blanchette-Mackie E, Londos C Perilipin, a major hormonally regulated adipocyte-specific phosphoprotein associated with the periphery of lipid storage droplets. J Biol Chem. 1991; 266:11341-6.

3. Welte MA. Expanding roles for lipid droplets. Curr Biol. 2015;25:R470-81.

4. Zehmer JK, Huang Y, Peng G, Pu J, Anderson RG, Liu P. A role for lipid droplets in inter-membrane lipid traffic. Proteomics. 2009;9:914-21.

5. Herker $\mathrm{E}, \mathrm{Ott} \mathrm{M}$. Unique ties between hepatitis $\mathrm{C}$ virus replication and intracellular lipids. Trends Endocrinol Metab. 2011;22:241-8. 
6. Greenberg AS, Coleman RA, Kraemer FB, McManaman JL, Obin MS, Puri V, et al. The role of lipid droplets in metabolic disease in rodents and humans J Clin Invest. 2011;121:2102.

7. Krahmer N, Farese RV Jr, Walther TC. Balancing the fat: lipid droplets and human disease. EMBO Mol Med. 2013;5:905-15.

8. Gross DA, Silver DL. Cytosolic lipid droplets: from mechanisms of fat storage to disease. Crit Rev Biochem Mol Biol. 2014;49:304-26.

9. Ducharme NA, Bickel PE. Minireview: lipid droplets in lipogenesis and lipolysis. Endocrinology. 2008;149:942-9.

10. Walther TC, Farese RV Jr. The life of lipid droplets. Biochim Biophys Acta. 2009;1791:459-66.

11. Kuma A, Mizushima N. Physiological role of autophagy as an intracellular recycling system: with an emphasis on nutrient metabolism. Semin Cell Dev Biol. 2010;21:683-90.

12. Oral O, Akkoc Y, Bayraktar O, Gozuacik D. Physiological and pathological significance of the molecular cross-talk between autophagy and apoptosis. Histol Histopathol. 2016:31:479-98.

13. Rabinowitz JD, White E. Autophagy and metabolism. Science. 2010;330: 1344-8

14. Cuervo AM, Dice JF. A receptor for the selective uptake and degradation of proteins by lysosomes. Science. 1996;273:501.

15. Orenstein SJ, Cuervo AM. Chaperone-mediated autophagy: molecular mechanisms and physiological relevance. Semin Cell Dev Biol. 2010;21:719-26.

16. Kaushik S, Cuervo AM. Chaperone-mediated autophagy: a unique way to enter the lysosome world. Trends Cell Biol. 2012;22:407-17.

17. Lizaso A, Tan K-T, Lee $\mathrm{Y}-\mathrm{H}$. $\beta$-adrenergic receptor-stimulated lipolysis requires the RAB7-mediated autolysosomal lipid degradation. Autophagy. 2013;9:1228-43.

18. Schroeder B, Schulze RJ, Weller SG, Sletten AC, Casey CA, McNiven MA. The small GTPase Rab7 as a central regulator of hepatocellular lipophagy. Hepatology. 2015;61:1896-907.

19. Kaushik S, Cuervo AM. Degradation of lipid droplet-associated proteins by chaperone-mediated autophagy facilitates lipolysis. Nat Cell Biol. 2015;17: 759-70

20. Kaushik S, Cuervo AM. AMPK-dependent phosphorylation of lipid droplet protein PLIN2 triggers its degradation by CMA. Autophagy. 2016;12:432-8.

21. Tauchi-Sato K, Ozeki S, Houjou T, Taguchi R, Fujimoto T. The surface of lipid droplets is a phospholipid monolayer with a unique Fatty Acid composition. J Biol Chem. 2002;277:44507-12.

22. Fujimoto T, Ohsaki Y, Cheng J, Suzuki M, Shinohara Y. Lipid droplets: a classic organelle with new outfits. Histochem Cell Biol. 2008;130:263-79.

23. Wilfling F, Haas JT, Walther TC, Farese RV Jr. Lipid droplet biogenesis. Curr Opin Cell Biol. 2014;29:39-45.

24. Bartz R, Li W-H, Venables B, Zehmer JK, Roth MR, Welti R, et al. Lipidomics reveals that adiposomes store ether lipids and mediate phospholipid traffic. J Lipid Res. 2007:48:837-47.

25. Blaner WS, O'Byrne SM, Wongsiriroj N, Kluwe J, D'Ambrosio DM, Jiang H, et al. Hepatic stellate cell lipid droplets: a specialized lipid droplet for retinoid storage. Biochim Biophys Acta Mol Cell Biol Lipids. 2009:1791:467-73.

26. Fujimoto T, Parton RG. Not just fat: the structure and function of the lipid droplet. Cold Spring Harb Perspect Biol. 2011;3

27. Wan HC, Melo RC, Jin Z, Dvorak AM, Weller PF. Roles and origins of leukocyte lipid bodies: proteomic and ultrastructural studies. FASEB J. 2007; 21:167-78.

28. Chitraju C, Trotzmuller M, Hartler J, Wolinski H, Thallinger GG, Lass A, et al. Lipidomic analysis of lipid droplets from murine hepatocytes reveals distinct signatures for nutritional stress. J Lipid Res. 2012:53:2141-52.

29. Penno A, Hackenbroich G, Thiele C. Phospholipids and lipid droplets. Biochim Biophys Acta. 1831;2013:589-94.

30. McIntosh AL, Storey SM, Atshaves BP. Intracellular lipid droplets contain dynamic pools of sphingomyelin: ADRP binds phospholipids with high affinity. Lipids. 2010;45:465-77.

31. Fei W, Shui G, Zhang Y, Krahmer N, Ferguson C, Kapterian TS, et al. A role for phosphatidic acid in the formation of "supersized" lipid droplets. PLoS Genet. 2011;7:e1002201.

32. Zanghellini J, Wodlei F, von Grünberg H. Phospholipid demixing and the birth of a lipid droplet. J Theor Biol. 2010;264:952-61.

33. Blouin CM, Le Lay S, Eberl A, Köfeler HC, Guerrera IC, Klein C, et al. Lipid droplet analysis in caveolin-deficient adipocytes: alterations in surface phospholipid composition and maturation defects. J Lipid Res. 2010;51:945-56.
34. Brasaemle DL, Wolins NE. Packaging of fat: an evolving model of lipid droplet assembly and expansion. J Biol Chem. 2012;287:2273-9.

35. Liu K, Czaja MJ. Regulation of lipid stores and metabolism by lipophagy. Cell Death Differ. 2013;20:3-11.

36. Singh R, Cuervo AM. Lipophagy: connecting autophagy and lipid metabolism. Int J Cell Biol. 2012;2012:282041.

37. Yang L, Ding Y, Chen Y, Zhang S, Huo C, Wang Y, et al. The proteomics of lipid droplets: structure, dynamics, and functions of the organelle conserved from bacteria to humans. J Lipid Res. 2012;53:1245-53.

38. Kalscheuer $R$, Wältermann M, Alvarez H, Steinbüchel A. Preparative isolation of lipid inclusions from Rhodococcus opacus and Rhodococcus ruber and identification of granule-associated proteins. Arch Microbiol. 2001;177:20-8.

39. Ding $Y$, Yang $L$, Zhang S, Wang Y, Du Y, Pu J, et al. Identification of the major functional proteins of prokaryotic lipid droplets. J Lipid Res. 2012;53:399-411.

40. Low KL, Shui G, Natter K, Yeo WK, Kohlwein SD, Dick T, et al. Lipid dropletassociated proteins are involved in the biosynthesis and hydrolysis of triacylglycerol in Mycobacterium bovis bacillus Calmette-Guerin. J Biol Chem. 2010;285:21662-70

41. Jolivet $\mathrm{P}$, Boulard $\mathrm{C}$, Bellamy $\mathrm{A}$, Larré $\mathrm{C}$, Barre $\mathrm{M}$, Rogniaux $\mathrm{H}$, et al. Protein composition of oil bodies from mature Brassica napus seeds. Proteomics. 2009;9:3268-84.

42. Jolivet P, Roux E, d'Andrea S, Davanture M, Negroni L, Zivy M, et al. Protein composition of oil bodies in Arabidopsis thaliana ecotype WS. Plant Physiol Biochem. 2004;42:501-9.

43. Athenstaedt K, Zweytick D, Jandrositz A, Kohlwein SD, Daum G. Identification and characterization of major lipid particle proteins of the yeast Saccharomyces cerevisiae. J Bacteriol. 1999;181:6441-8.

44. Grillitsch K, Connerth M, Köfeler H, Arrey TN, Rietschel B, Wagner B, et al. Lipid particles/droplets of the yeast Saccharomyces cerevisiae revisited: lipidome meets proteome. Biochim Biophys Acta Mol Cell Biol Lipids. 1811; 2011:1165-76.

45. Beller M, Riedel D, Jänsch L, Dieterich $G$, Wehland J, Jäckle $H$, et al. Characterization of the Drosophila lipid droplet subproteome. Mol Cell Proteomics. 2006:5:1082-94.

46. Soulages JL, Firdaus SJ, Hartson S, Chen X, Howard AD, Arrese EL. Developmental changes in the protein composition of Manduca sexta lipid droplets. Insect Biochem Mol Biol. 2012;42:305-20.

47. Bouchoux J, Beilstein F, Pauquai T, Guerrera IC, Chateau D, Ly N, et al. The proteome of cytosolic lipid droplets isolated from differentiated Caco-2/TC7 enterocytes reveals cell-specific characteristics. Biol Cell. 2011;103:499-517.

48. Sato S, Fukasawa M, Yamakawa Y, Natsume T, Suzuki T, Shoji I, et al. Proteomic profiling of lipid droplet proteins in hepatoma cell lines expressing hepatitis C virus core protein. J Biochem. 2006;139:921-30.

49. Brasaemle DL, Dolios G, Shapiro L, Wang R. Proteomic analysis of proteins associated with lipid droplets of basal and lipolytically stimulated 3T3-L adipocytes. J Biol Chem. 2004;279:46835-42.

50. Bickel PE, Tansey JT, Welte MA. PAT proteins, an ancient family of lipid droplet proteins that regulate cellular lipid stores. Biochim Biophys Acta Mol Cell Biol Lipids. 2009:1791:419-40.

51. Tansey J, Sztalryd C, Gruia-Gray J, Roush D, Zee J, Gavrilova O, et al. Perilipin ablation results in a lean mouse with aberrant adipocyte lipolysis, enhanced leptin production, and resistance to diet-induced obesity. Proc Natl Acad Sci. 2001:98:6494-9.

52. Hodges BD, Wu CC. Proteomic insights into an expanded cellular role for cytoplasmic lipid droplets. J Lipid Res. 2010:51:262-73.

53. Welte MA. Proteins under new management: lipid droplets deliver. Trends Cell Biol. 2007:17:363-9.

54. Yu W, Cassara J, Weller PF. Phosphatidylinositide 3-kinase localizes to cytoplasmic lipid bodies in human polymorphonuclear leukocytes and other myeloid-derived cells. Blood. 2000;95:1078-85.

55. Yu W, Bozza PT, Tzizik DM, Gray JP, Cassara J, Dvorak AM, et al. Cocompartmentalization of MAP kinases and cytosolic phospholipase A2 at cytoplasmic arachidonate-rich lipid bodies. Am J Pathol. 1998;152:759.

56. Smart EJ, Graf GA, McNiven MA, Sessa WC, Engelman JA, Scherer PE, et al. Caveolins, liquid-ordered domains, and signal transduction. Mo Cell Biol. 1999:19:7289-304.

57. Kurzchalia TV, Partan RG. Membrane microdomains and caveolae. Curr Opin Cell Biol. 1999:11:424-31.

58. Fujimoto T, Kogo H, Ishiguro K, Tauchi K, Nomura R. Caveolin-2 is targeted to lipid droplets, a new "membrane domain" in the cell. J Cell Biol. 2001; 152:1079-86. 
59. van Meer G. Caveolin, cholesterol, and lipid droplets? J Cell Biol. 2001;152:F29-34.

60. Uzbekov R, Roingeard P. Nuclear lipid droplets identified by electron microscopy of serial sections. BMC Res Notes. 2013;6:386.

61. Layerenza J, González P, de Bravo MG, Polo M, Sisti M, Ves-Losada A Nuclear lipid droplets: a novel nuclear domain. Biochim Biophys Acta Mol Cell Biol Lipids. 1831;2013:327-40.

62. Wältermann M, Hinz A, Robenek H, Troyer D, Reichelt R, Malkus U, et al. Mechanism of lipid-body formation in prokaryotes: how bacteria fatten up. Mol Microbiol. 2005;55:750-63.

63. Ploegh HL. A lipid-based model for the creation of an escape hatch from the endoplasmic reticulum. Nature. 2007:448:435-8.

64. Zweytick D, Athenstaedt K, Daum G. Intracellular lipid particles of eukaryotic cells. Biochim Biophys Acta Rev Biomembr. 2000;1469:101-20.

65. Long AP, Manneschmidt AK, VerBrugge B, Dortch MR, Minkin SC, Prater KE, et al. Lipid droplet de novo formation and fission are linked to the cell cycle in fission yeast. Traffic. 2012;13:705-14.

66. Ohsaki Y, Suzuki M, Fujimoto T. Open questions in lipid droplet biology. Chem Biol. 2014;21:86-96.

67. Soni KG, Mardones GA, Sougrat R, Smirnova E, Jackson CL, Bonifacino JS Coatomer-dependent protein delivery to lipid droplets. J Cell Sci. 2009; 122:1834-41.

68. Ohsaki Y, Cheng J, Suzuki M, Fujita A, Fujimoto T. Lipid droplets are arrested in the ER membrane by tight binding of lipidated apolipoprotein B-100. J Cell Sci. 2008;121:2415-22.

69. Ellis JM, Frahm JL, Li LO, Coleman RA. Acyl-coenzyme A synthetases in metabolic control. Curr Opin Lipidol. 2010;21:212

70. Khelef N, Buton X, Beatini N, Wang H, Meiner V, Chang T-Y, et al. Immunolocalization of Acyl-Coenzyme A: CholesterolO-Acyltransferase in Macrophages. J Biol Chem. 1998;273:11218-24.

71. Stone SJ, Levin MC, Zhou P, Han J, Walther TC, Farese RV Jr. The endoplasmic reticulum enzyme DGAT2 is found in mitochondria-associated membranes and has a mitochondrial targeting signal that promotes its association with mitochondria. J Biol Chem. 2009;284:5352-61.

72. Markgraf DF, Klemm RW, Junker M, Hannibal-Bach HK, Ejsing CS, Rapoport TA. An ER protein functionally couples neutral lipid metabolism on lipid droplets to membrane lipid synthesis in the ER. Cell Rep. 2014;6:44-55.

73. Yang H, Galea A, Sytnyk V, Crossley M. Controlling the size of lipid droplets: lipid and protein factors. Curr Opin Cell Biol. 2012;24:509-16.

74. Zhang S, Wang Y, Cui L, Deng Y, Xu S, Yu J, et al. Morphologically and Functionally Distinct Lipid Droplet Subpopulations. Sci Rep. 2016;6

75. Thiam AR, Beller M. The why, when and how of lipid droplet diversity. J Cell Sci. 2017. Doi:10.1242/jcs.192021.

76. Boström P, Andersson L, Rutberg M, Perman J, Lidberg U, Johansson BR, et al. SNARE proteins mediate fusion between cytosolic lipid droplets and are implicated in insulin sensitivity. Nat Cell Biol. 2007;9:1286-93.

77. Boström P, Rutberg M, Ericsson J, Holmdahl P, Andersson L, Frohman MA, et al. Cytosolic lipid droplets increase in size by microtubule-dependent complex formation. Arterioscler Thromb Vasc Biol. 2005;25:1945-51.

78. Digel $M$, Ehehalt R, Fullekrug J. Lipid droplets lighting up: insights from live microscopy. FEBS Lett. 2010;584:2168-75.

79. Guo Y, Walther TC, Rao M, Stuurman N, Goshima G, Terayama K, et al. Functional genomic screen reveals genes involved in lipid-droplet formation and utilization. Nature. 2008;453:657-61.

80. Gong J, Sun Z, Wu L, Xu W, Schieber N, Xu D, et al. Fsp27 promotes lipid droplet growth by lipid exchange and transfer at lipid droplet contact sites. J Cell Biol. 2011;195:953-63.

81. Puri V, Konda S, Ranjit S, Aouadi M, Chawla A, Chakladar A, et al. Fat-specific protein 27, a novel lipid droplet protein that enhances triglyceride storage. J Biol Chem. 2007;282:34213-8.

82. Keller P, Petrie JT, De Rose P, Gerin I, Wright WS, Chiang S-H, et al. Fatspecific protein 27 regulates storage of triacylglycerol. J Biol Chem. 2008; 283:14355-65

83. Fujimoto Y, Itabe H, Kinoshita T, Homma KJ, Onoduka J, Mori M, et al. Involvement of ACSL in local synthesis of neutral lipids in cytoplasmic lipid droplets in human hepatocyte HuH7. J Lipid Res. 2007;48:1280-92.

84. Moessinger C, Kuerschner L, Spandl J, Shevchenko A, Thiele C. Human lysophosphatidylcholine acyltransferases 1 and 2 are located in lipid droplets where they catalyze the formation of phosphatidylcholine. J Biol Chem. 2011;286:21330-9.

85. Roingeard P, Melo RC. Lipid droplet hijacking by intracellular pathogens. Cell Microbiol. 2016;19:e12688.
86. Miyanari Y, Atsuzawa K, Usuda N, Watashi K, Hishiki T, Zayas M, et al. The lipid droplet is an important organelle for hepatitis $C$ virus production. Nat Cell Biol. 2007;9:1089-97.

87. Hourioux C, Patient R, Morin A, Blanchard E, Moreau A, Trassard S, et al. The genotype 3-specific hepatitis $C$ virus core protein residue phenylalanine 164 increases steatosis in an in vitro cellular model. Gut. 2007;56:1302-8.

88. Samsa MM, Mondotte JA, Iglesias NG, Assunção-Miranda I, Barbosa-Lima G, Da Poian AT, et al. Dengue virus capsid protein usurps lipid droplets for viral particle formation. PLoS Pathog. 2009;5:e1000632.

89. Cermelli S, Guo Y, Gross SP, Welte MA. The lipid-droplet proteome reveals that droplets are a protein-storage depot. Curr Biol. 2006;16:1783-95.

90. Gómez-Ramos P, Asunción MM. Ultrastructural localization of intraneuronal Abeta-peptide in Alzheimer disease brains. J Alzheimers Dis. 2007;11:53-9.

91. Outeiro TF, Lindquist S. Yeast cells provide insight into alpha-synuclein biology and pathobiology. Science. 2003;302:1772-5.

92. Cole NB, Murphy DD, Grider T, Rueter S, Brasaemle D, Nussbaum RL. Lipid droplet binding and oligomerization properties of the Parkinson's disease protein alpha-synuclein. J Biol Chem. 2002;277:6344-52.

93. Moldavski O, Amen T, Levin-Zaidman S, Eisenstein M, Rogachev I, Brandis A, et al. Lipid Droplets Are Essential for Efficient Clearance of Cytosolic Inclusion Bodies. Dev Cell. 2015;33:603-10.

94. Souza SC, Muliro KV, Liscum L, Lien P, Yamamoto MT, Schaffer JE, et al. Modulation of hormone-sensitive lipase and protein kinase A-mediated lipolysis by perilipin A in an adenoviral reconstituted system. J Biol Chem. 2002;277:8267-72

95. Gruber A, Cornaciu I, Lass A, Schweiger M, Poeschl M, Eder C, et al. The Nterminal region of comparative gene identification-58 (CGl-58) is important for lipid droplet binding and activation of adipose triglyceride lipase. J Biol Chem. 2010;285:12289-98.

96. Zechner R, Zimmermann R, Eichmann TO, Kohlwein SD, Haemmerle G, Lass A, et al. FAT SIGNALS-lipases and lipolysis in lipid metabolism and signaling. Cell Metab. 2012;15:279-91.

97. Zimmermann R, Strauss JG, Haemmerle G, Schoiswohl G, BirnerGruenberger $\mathrm{R}$, Riederer $\mathrm{M}$, et al. Fat mobilization in adipose tissue is promoted by adipose triglyceride lipase. Science. 2004;306:1383-6.

98. Schweiger M, Schreiber R, Haemmerle G, Lass A, Fledelius C, Jacobsen P, et al. Adipose triglyceride lipase and hormone-sensitive lipase are the major enzymes in adipose tissue triacylglycerol catabolism. J Biol Chem. 2006;281:40236-41.

99. J-i O, Ishibashi S, Oka T, Yagyu H, Tozawa R, Fujimoto A, et al. Targeted disruption of hormone-sensitive lipase results in male sterility and adipocyte hypertrophy, but not in obesity. Proc Natl Acad Sci. 2000;97:787-92.

100. Haemmerle G, Zimmermann R, Hayn M, Theussl C, Waeg G, Wagner E, et al. Hormone-sensitive lipase deficiency in mice causes diglyceride accumulation in adipose tissue, muscle, and testis. J Biol Chem. 2002;277:4806-15.

101. Taschler U, Radner FP, Heier C, Schreiber R, Schweiger M, Schoiswohl G, et al. Monoglyceride lipase deficiency in mice impairs lipolysis and attenuates diet-induced insulin resistance. J Biol Chem. 2011;286:17467-77.

102. D'Andrea S. Lipid droplet mobilization: The different ways to loosen the purse strings. Biochimie. 2016;120:17-27. doi:10.1016/j.biochi.2015.07.010.

103. Singh R, Kaushik S, Wang Y, Xiang Y, Novak I, Komatsu M, et al. Autophagy regulates lipid metabolism. Nature. 2009;458:1131-5.

104. Schulze RJ, Weller SG, Schroeder B, Krueger EW, Chi S, Casey CA, et al. Lipid droplet breakdown requires dynamin 2 for vesiculation of autolysosomal tubules in hepatocytes. J Cell Biol. 2013;203:315-26.

105. Stenmark H. Rab GTPases as coordinators of vesicle traffic. Nat Rev Mol Cell Biol. 2009;10:513-25

106. Gutierrez MG, Munafó DB, Berón W, Colombo MI. Rab7 is required for the normal progression of the autophagic pathway in mammalian cells. J Cell Sci. 2004;117:2687-97.

107. Liu Y, Takahashi Y, Desai N, Zhang J, Serfass JM, Shi Y-G, et al. Bif-1 deficiency impairs lipid homeostasis and causes obesity accompanied by insulin resistance. Sci Rep. 2016;6

108. Yang L, Li P, Fu S, Calay ES, Hotamisligil GS. Defective hepatic autophagy in obesity promotes ER stress and causes insulin resistance. Cell Metab. 2010;11:467-78

109. Martinez-Vicente M, Talloczy Z, Wong E, Tang G, Koga H, Kaushik S, et al. Cargo recognition failure is responsible for inefficient autophagy in Huntington's disease. Nat Neurosci. 2010;13:567-76.

110. Kaushik S, Rodriguez-Navarro JA, Arias E, Kiffin R, Sahu S, Schwartz GJ, et al. Autophagy in hypothalamic AgRP neurons regulates food intake and energy balance. Cell Metab. 2011;14:173-83. 
111. Ouimet M, Franklin V, Mak E, Liao X, Tabas I, Marcel YL. Autophagy regulates cholesterol efflux from macrophage foam cells via lysosomal acid lipase. Cell Metab. 2011;13:655-67.

112. Khaldoun SA, Emond-Boisjoly MA, Chateau D, Carriere V, Lacasa M, Rousset $\mathrm{M}$, et al. Autophagosomes contribute to intracellular lipid distribution in enterocytes. Mol Biol Cell. 2014;25:118-32.

113. Hubbard VM, Valdor R, Patel B, Singh R, Cuervo AM, Macian F. Macroautophagy regulates energy metabolism during effector $T$ cell activation. J Immunol. 2010;185:7349-57.

114. Xu X, Grijalva A, Skowronski A, van Eijk M, Serlie MJ, Ferrante AW. Obesity activates a program of lysosomal-dependent lipid metabolism in adipose tissue macrophages independently of classic activation. Cell Metab. 2013:18:816-30

115. Kaini RR, Hu C-AA. Synergistic killing effect of chloroquine and androgen deprivation in LNCaP cells. Biochem Biophys Res Commun. 2012;425:150-6.

116. van Zutphen T, Todde $V$, de Boer R, Kreim M, Hofbauer HF, Wolinski H, et al. Lipid droplet autophagy in the yeast Saccharomyces cerevisiae. Mol Biol Cell. 2014;25:290-301.

117. Lapierre LR, Gelino S, Meléndez A, Hansen M. Autophagy and lipid metabolism coordinately modulate life span in germline-less C. elegans. Curr Biol. 2011:21:1507-14.

118. Nguyen LN, Bormann J, Le GTT, Stärkel C, Olsson S, Nosanchuk JD, et al. Autophagy-related lipase FgATG15 of Fusarium graminearum is important for lipid turnover and plant infection. Fungal Genet Biol. 2011;48:217-24.

119. Velikkakath AKG, Nishimura T, Oita E, Ishihara N, Mizushima N. Mammalian Atg2 proteins are essential for autophagosome formation and important for regulation of size and distribution of lipid droplets. Mol Biol Cell. 2012;23:896-909.

120. Rambold AS, Cohen S, Lippincott-Schwartz J. Fatty acid trafficking in starved cells: regulation by lipid droplet lipolysis, autophagy, and mitochondrial fusion dynamics. Dev Cell. 2015;32:678-92

121. Martinez-Lopez N, Garcia-Macia M, Sahu S, Athonvarangkul D, Liebling E, Merlo P, et al. Autophagy in the CNS and Periphery Coordinate Lipophagy and Lipolysis in the Brown Adipose Tissue and Liver. Cell Metab. 2016;23: 113-27

122. Dupont N, Chauhan S, Arko-Mensah J, Castillo EF, Masedunskas A, Weigert R, et al. Neutral lipid stores and lipase PNPLA5 contribute to autophagosome biogenesis. Curr Biol. 2014;24:609-20.

123. Shpilka T, Welter E, Borovsky N, Amar N, Mari M, Reggiori F, et al. Lipid droplets and their component triglycerides and steryl esters regulate autophagosome biogenesis. EMBO J. 2015;34:2117-31.

124. Velázquez AP, Tatsuta T, Ghillebert R, Drescher I, Graef M. Lipid dropletmediated ER homeostasis regulates autophagy and cell survival during starvation. J Cell Biol. 2016;212:621-31.

125. Reue K. A thematic review series: lipid droplet storage and metabolism: from yeast to man. J Lipid Res. 2011;52:1865-8.

126. Fischer J, Lefèvre C, Morava E, Mussini J-M, Laforêt $P$, Negre-Salvayre A, et al. The gene encoding adipose triglyceride lipase (PNPLA2) is mutated in neutral lipid storage disease with myopathy. Nat Genet. 2007:39:28-30.

127. Lefèvre C, Jobard F, Caux F, Bouadjar B, Karaduman A, Heilig R, et al. Mutations in $\mathrm{CGl}-58$, the gene encoding a new protein of the esterase/ lipase/thioesterase subfamily, in Chanarin-Dorfman syndrome. Am J Hum Genet. 2001:69:1002-12.

128. Emre S, Ünver N, Evans SE, Yüzbaşıŏlu A, Gürakan F, Gümrük F, et al. Molecular analysis of Chanarin-Dorfman syndrome (CDS) patients: Identification of novel mutations in the ABHD5 gene. Eur J Med Genet. 2010;53:141-4

129. Nur BG, Gencpinar P, Yuzbasıoglu A, Emre SD, Mihci E. Chanarin-Dorfman syndrome: Genotype-Phenotype Correlation. Eur J Med Genet. 2015; 58:238-42.

130. Waheed N, Cheema HA, Suleman H, Mushtaq I, Fayyaz Z. Chanarin-Dorfman Syndrome. J Coll Physicians Surg Pak. 2016;26:787.

131. Schweiger M, Lass A, Zimmermann R, Eichmann TO, Zechner R. Neutral lipid storage disease: genetic disorders caused by mutations in adipose triglyceride lipase/PNPLA2 or CGI-58/ABHD5. Am J Physiol Endocrinol Metab. 2009:297:E289-E96.

132. Ghosh AK, Ramakrishnan G, Chandramohan C, Rajasekharan R. CGI-58, the causative gene for Chanarin-Dorfman syndrome, mediates acylation of lysophosphatidic acid. J Biol Chem. 2008;283:24525-33.

133. Madrigal-Matute J, Cuervo AM. Regulation of Liver Metabolism by Autophagy. Gastroenterology. 2016;150:328-39.
134. Kovsan J, Bluher M, Tarnovscki T, Kloting N, Kirshtein B, Madar L, et al. Altered autophagy in human adipose tissues in obesity. J Clin Endocrinol Metab. 2011;96:E268-77.

135. Ost A, Svensson K, Ruishalme I, Brannmark C, Franck N, Krook H, et al. Attenuated mTOR signaling and enhanced autophagy in adipocytes from obese patients with type 2 diabetes. Mol Med. 2010;16:235-46.

136. Hubler MJ, Kennedy AJ. Role of lipids in the metabolism and activation of immune cells. J Nutr Biochem. 2016;34:1-7.

137. Liu K, Zhao E, llyas G, Lalazar G, Lin Y, Haseeb M, et al. Impaired macrophage autophagy increases the immune response in obese mice by promoting proinflammatory macrophage polarization. Autophagy. 2015;11:271-84.

138. Grijalva A, Xu X, Ferrante AW. Autophagy is dispensable for macrophage mediated lipid homeostasis in adipose tissue. Diabetes. 2016. 2016;65(4):967-80. doi:10.2337/db15-1219.

139. Czaja MJ. Function of autophagy in nonalcoholic fatty liver disease. Dig Dis Sci. 2016;61:1304-13

140. Dolganiuc A, Thomes PG, Ding WX, Lemasters JJ, Donohue TM. Autophagy in Alcohol-Induced Liver Diseases. Alcohol Clin Exp Res. 2012;36:1301-8.

141. Ji G, Wang Y, Deng Y, Li X, Jiang Z. Resveratrol ameliorates hepatic steatosis and inflammation in methionine/choline-deficient diet-induced steatohepatitis through regulating autophagy. Lipids Health Dis. 2015;14:1.

142. Chen R, Wang Q, Song S, Liu F, He B, Gao X. Protective role of autophagy in methionine-choline deficient diet-induced advanced nonalcoholic steatohepatitis in mice. Eur J Pharmacol. 2016;770:126-33.

143. Ding WX, Li M, Chen X, Ni HM, Lin CW, Gao W, et al. Autophagy reduces acute ethanol-induced hepatotoxicity and steatosis in mice. Gastroenterology. 2010;139:1740-52.

144. Wang Y, Singh R, Xiang Y, Czaja MJ. Macroautophagy and chaperonemediated autophagy are required for hepatocyte resistance to oxidant stress. Hepatology. 2010;52:266-77.

145. Lu Y, Cederbaum Al. Autophagy Protects against CYP2E1/Chronic EthanolInduced Hepatotoxicity. Biomol Ther. 2015;5:2659-74.

146. Thoen LF, Guimarães EL, Dollé L, Mannaerts I, Najimi M, Sokal E, et al. A role for autophagy during hepatic stellate cell activation. J Hepatol. 2011;55:1353-60.

147. Hernández-Gea V, Ghiassi-Nejad Z, Rozenfeld R, Gordon R, Fiel MI, Yue Z, et al. Autophagy releases lipid that promotes fibrogenesis by activated hepatic stellate cells in mice and in human tissues. Gastroenterology. 2012;142:93846.

148. Hidvegi T, Ewing M, Hale P, Dippold C, Beckett C, Kemp C, et al. An autophagy-enhancing drug promotes degradation of mutant a1-antitrypsin $Z$ and reduces hepatic fibrosis. Science. 2010;329:229-32.

149. Rautou P-E, Cazals-Hatem D, Feldmann G, Mansouri A, Grodet A, Barge S, et al. Changes in autophagic response in patients with chronic hepatitis $C$ virus infection. Am J Pathol. 2011;178:2708-15.

150. Taguwa S, Kambara H, Fujita N, Noda T, Yoshimori T, Koike K, et al. Dysfunction of autophagy participates in vacuole formation and cell death in cells replicating hepatitis C virus. J Virol. 2011;85:13185-94.

151. Dash S, Chava S, Chandra PK, Aydin Y, Balart LA, Wu T. Autophagy in hepatocellular carcinomas: From pathophysiology to therapeutic response. Hepat Med. 2016:8:9.

152. Reynolds T. Cholesteryl ester storage disease: a rare and possibly treatable cause of premature vascular disease and cirrhosis. J Clin Pathol. 2013: doi:10.1136/jclinpath-2012-201302.

153. Assmann G, Fredrickson D. Acid lipase deficiency: Wolman's disease and cholesteryl ester storage disease. In: Stanbury JB et al., editors. Metabolic basis of inherited disease. New York: McGraw Hill; 1983.

154. Su YR, Dove DE, Major AS, Hasty AH, Boone B, Linton MF, et al. Reduced ABCA1-Mediated Cholesterol Efflux and Accelerated Atherosclerosis in Apolipoprotein E-Deficient Mice Lacking Macrophage-Derived ACAT1. Circulation. 2005;111:2373-81.

155. Larigauderie G, Furman C, Jaye M, Lasselin C, Copin C, Fruchart J-C, et al. Adipophilin enhances lipid accumulation and prevents lipid efflux from THP-1 macrophages potential role in atherogenesis. Arterioscler Thromb Vasc Biol. 2004;24:504-10.

156. Paul A, Chang BH-J, Li L, Yechoor VK, Chan L. Deficiency of adipose differentiation-related protein impairs foam cell formation and protects against atherosclerosis. Circ Res. 2008;102:1492-501.

157. Wang T, Zhang L, Hu J, Duan Y, Zhang M, Lin J, et al. Mst1 participates in the atherosclerosis progression through macrophage autophagy inhibition and macrophage apoptosis enhancement. J Mol Cell Cardiol. 2016;98:108-16. 
158. Garg A, Agarwal AK. Lipodystrophies: disorders of adipose tissue biology. Biochim Biophys Acta. 2009;1791:507-13.

159. Hegele RA. Phenomics, lipodystrophy, and the metabolic syndrome. Trends Cardiovasc Med. 2004:14:133-7.

160. Cho SY, Shin ES, Park PJ, Shin DW, Chang HK, Kim D, et al. Identification of mouse Prp19p as a lipid droplet-associated protein and its possible involvement in the biogenesis of lipid droplets. J Biol Chem. 2007;282:2456-65.

161. III JRY, McManaman JL. Proteomics reveal a link between the endoplasmic reticulum and lipid secretory mechanisms in mammary epithelial cells. Electrophoresis. 2000;21:3470-82

162. Liu P, Ying Y, Zhao Y, Mundy DI, Zhu M, Anderson RG. Chinese hamster ovary K2 cell lipid droplets appear to be metabolic organelles involved in membrane traffic. J Biol Chem. 2004;279:3787-92.

163. Turró S, Ingelmo-Torres M, Estanyol JM, Tebar F, Fernández MA, Albor CV, et al. Identification and characterization of associated with lipid droplet protein 1: A novel membrane-associated protein that resides on hepatic lipid droplets. Traffic. 2006;7:1254-69.

164. Wan H-C, Melo RC, Jin Z, Dvorak AM, Weller PF. Roles and origins of leukocyte lipid bodies: proteomic and ultrastructural studies. FASEB J. 2007;21:167-78.

165. Umlauf E, Csaszar E, Moertelmaier M, Schuetz GJ, Parton RG, Prohaska R. Association of stomatin with lipid bodies. J Biol Chem. 2004;279:23699-709.

166. Fujimoto Y, Itabe H, Sakai J, Makita M, Noda J, Mori M, et al. Identification of major proteins in the lipid droplet-enriched fraction isolated from the human hepatocyte cell line HuH7. Biochim Biophys Acta Mol Cell Res. 2004;1644:47-59.

167. Wang H, Wei E, Quiroga AD, Sun X, Touret N, Lehner R. Altered lipid droplet dynamics in hepatocytes lacking triacylglycerol hydrolase expression. Mol Biol Cell. 2010;21:1991-2000.

168. Khor VK, Ahrends R, Lin Y, Shen W-J, Adams CM, Roseman AN, et al. The proteome of cholesteryl-ester-enriched versus triacylglycerol-enriched lipid droplets. PLoS One. 2014:9:e105047.

169. Thiel K, Heier C, Haberl V, Thul PJ, Oberer M, Lass A, et al. The evolutionarily conserved protein CG9186 is associated with lipid droplets, required for their positioning and for fat storage. J Cell Sci. 2013;126:2198-212.

170. Goo Y-H, Son S-H, Kreienberg PB, Paul A. Novel Lipid Droplet-Associated Serine Hydrolase Regulates Macrophage Cholesterol MobilizationSignificance. Arterioscler Thromb Vasc Biol. 2014;34:386-96.

171. Heid H, Rickelt S, Zimbelmann R, Winter S, Schumacher H, Dörflinger $Y$, et al. On the formation of lipid droplets in human adipocytes: the organization of the perilipin-vimentin cortex. PLoS One. 2014;9:e90386.

172. Martin S, Parton RG. Caveolin, cholesterol, and lipid bodies. Semin Cell Dev Biol. 2005:163-74.

173. Pol A, Martin S, Fernández MA, Ingelmo-Torres M, Ferguson C, Enrich C, et al. Cholesterol and fatty acids regulate dynamic caveolin trafficking through the Golgi complex and between the cell surface and lipid bodies. Mol Biol Cell. 2005;16:2091-105.

174. Ohsaki Y, Cheng J, Fujita A, Tokumoto T, Fujimoto T. Cytoplasmic lipid droplets are sites of convergence of proteasomal and autophagic degradation of apolipoprotein B. Mol Biol Cell. 2006;17:2674-83.

175. Shi ST, Polyak SJ, Tu H, Taylor DR, Gretch DR, Lai MM. Hepatitis C virus NS5A colocalizes with the core protein on lipid droplets and interacts with apolipoproteins. Virology. 2002;292:198-210.

176. Hope RG, Murphy DJ, McLauchlan J. The domains required to direct core proteins of hepatitis C virus and GB virus-B to lipid droplets share common features with plant oleosin proteins. J Biol Chem. 2002;277:4261-70.

177. Alonzi T, Agrati C, Costabile B, Cicchini C, Amicone L, Cavallari C, et al. Steatosis and intrahepatic lymphocyte recruitment in hepatitis $C$ virus transgenic mice. J Gen Virol. 2004;85:1509-20.

178. Zhang H, Wang Y, Li J, Yu J, Pu J, Li L, et al. Proteome of skeletal muscle lipid droplet reveals association with mitochondria and apolipoprotein al. Proteome Res. 2011;10:4757-68.

\section{Submit your next manuscript to BioMed Central and we will help you at every step:}

- We accept pre-submission inquiries

- Our selector tool helps you to find the most relevant journal

- We provide round the clock customer support

- Convenient online submission

- Thorough peer review

- Inclusion in PubMed and all major indexing services

- Maximum visibility for your research

Submit your manuscript at www.biomedcentral.com/submit

) Biomed Central 